\title{
Paixões amorosas, paixões políticas
}

\author{
Fábio Ramalho*
}

\section{Resumo}

Este ensaio pretende tomar parte nos estudos sobre as prolíficas relações entre cinema e nostalgia. Nele, proponho discutir em que medida o filme Les roseaux sauvages (1994), do diretor francês André Téchiné, delineia a juventude como um momento de abertura, intensificação e incerteza, ao situar os dramas e conflitos de seus personagens no contexto da França de 1962, durante os últimos desdobramentos da guerra pela independência da Argélia. A despeito da temática do filme e de seus traços potencialmente autobiográficos, busco argumentar que a nostalgia deveria ser aqui explorada menos na dimensão autoral do que através da revisitação de artefatos culturais, bem como nas articulações propostas entre amor, história e política. A nostalgia constitui uma estrutura complexa de múltiplas temporalidades sobrepostas na qual o espectador está necessariamente implicado. Nesse sentido, ela envolve um engajamento afetivo e uma resposta subjetiva que busco explicitar.

\section{Palavras-chave}

Cinema. Nostalgia. Juventude. Amor. Política.

\section{$\mathbf{I}$}

O imaginário político ocidental parece ter reservado aos jovens a primazia da radicalidade. Diante da fixidez dos maduros, de suas posições consolidadas e de sua exercitada moderação, foi a juventude - esta categoria amparada menos por aspectos cronológicos do que por uma série de valores culturais definidores ${ }^{1}$ - que teve sua imagem mais fortemente vinculada à capacidade de operar transformações decisivas na sociedade.

\footnotetext{
* Doutorando em Comunicação, PPGCOM-UFPE.

${ }^{1}$ Beatriz Sarlo (2004, p. 36) situa nos anos 1950 o início da conformação daquilo que poderia ser chamado de um estilo jovem e, já no marco da cultura pós-moderna, observa: "A infância quase desapareceu, encurralada por uma adolescência precocíssima. A primeira juventude se prolonga até depois dos 30 anos. Um terço da vida se desenvolve sob o rótulo de juventude, tão convencional quanto quaisquer outros rótulos. Todo mundo sabe que esses limites, aceitos como indicações precisas, variam o tempo todo". Em suma, afirma: "a juventude não é uma idade e sim uma estética da vida cotidiana."
} 
Instavelmente situados em algum ponto anterior ao erguimento de todas as defesas e beneficiados pela ausência de uma longa trajetória cujo peso os obrigaria a constantemente ter de prestar contas com o passado, os jovens encontrariam a possibilidade de uma total abertura para o novo, de uma vida sem grandes amarras ${ }^{2}$. E, para o caso de que algo dê errado, contam ao menos com sua potência restauradora, uma força curativa capaz de sanar todas as feridas. Prosperou, assim, em múltiplas vertentes, o elogio à ampla capacidade que teriam os jovens de enfrentar adversidades, superar perdas, alternar pontos de vista, subverter posicionamentos. Acepção positiva que não seria, de fato, a única configuração possível: seu reverso é a imagem do jovem inconsequente, alienado e perverso que encontrou também expressiva permanência na cultura contemporânea. Entre um polo e outro, inúmeras variações vêm consolidar o par juventude-política como questão relevante para a produção contemporânea; como recurso para fixar os traços que indicariam os rumos de um processo histórico, bem como os efeitos sobre a comunidade nacional, política ou afetiva que o testemunha.

Centrando-me em uma vertente da questão - aquela que enfatiza a posição do jovem como sujeito político implicado e comprometido com os problemas de seu tempo - proponho um filme, em particular, como chave para discutir certas maneiras pelas quais a cultura visual coloca essa relação; como, em certa medida, tal cultura apresenta eventos históricos como marcos geracionais que definem a experiência de uma época. Em Les roseaux sauvages (1994), de André Téchiné, a narrativa se estabelece em torno a quatro jovens que enfrentam seus próprios dilemas durante os desdobramentos finais da guerra pela independência da Argélia, no ano de 1962. Maïté (Élodie Bouchez) é filha de uma professora militante do partido comunista, Madame Alvaréz (Michèle Moretti), e compartilha com a mãe muitas de suas convicções. Arredia à possibilidade de um interesse sexual ou romântico pelos homens, mantém uma relação deserotizada com o jovem François (Gaël Morel), relação que se desestabiliza quando o rapaz vivencia uma experiência sexual com seu colega de quarto, Serge (Stéphane Rideau). Filho de camponeses, Serge sustenta um posicionamento mais prático em relação às perspectivas abertas para o seu futuro, e as consequências da guerra para a vida de sua família o colocam mais fortemente em tensão com Henri (Frédéric Gorny), filho de franceses nascido na colônia e contrário à independência argelina.

Dentre os muitos olhares que o filme possibilita, neste ensaio o foco recai sobre a possibilidade de uma recuperação nostálgica da adolescência como momento de intensificação de experiências que implicam um engajamento político e afetivo. Se o filme se presta a uma apreciação deste tipo, busco argumentar que isto se dá

\footnotetext{
2 "When I was seventeen I could do anything. It was so easy, my emotions were so close to the surface", rememora a personagem interpretada por Gena Rowlands, logo no início de Opening Night (1977), filme de John Cassavetes. É em torno a esse "efeito de superfície" que foi sendo construída no cinema uma imagem erótica, ingênua, desafiadora, radiante e aberta à renovação - imagem que seria, por isso mesmo, muitas vezes perturbadoramente ambivalente para os mais velhos. Não obstante, talvez nem seja necessário apontar uma figura que traduza esse arquétipo - e ainda que o duplo de Myrtle Gordon no filme de Cassavetes sem dúvida nos conceda um bom exemplo. Mais do que uma imagem específica, tais aspectos da juventude conformam um imaginário difuso e persistente, uma simbologia historicamente constituída.
} 
sobretudo pelo estabelecimento de um modo peculiar de relacionar política, juventude e história. Recorro ainda a outros filmes para ampliar o escopo das questões propostas e estabelecer aproximações.

\section{II}

Na esfera dos debates políticos, a evocação das qualidades atribuídas aos jovens não deixou de postular a diminuição do hiato existente entre as vivências pessoais e a experiência social. Um "mito da juventude" foi tecido, posto em circulação e frequentemente reiterado, ainda que não isento de eventuais ataques ou da confrontação com alguns contrapontos menos elogiosos. É contra esse mito que um jovem se volta em Chronique d'un été (1960) - documentário dirigido por Edgar Morin e Jean Rouch, cujo fio condutor é uma vontade de política que orienta os questionamentos de seus personagens acerca da possibilidade de qualquer compromisso, no momento em que um desencantamento em relação ao trabalho, às relações amorosas e à cidade parece suplantar qualquer tentativa de conectar-se ao outro. Diante do fardo que o protagonismo atribuído a ele e a seus pares lhes reserva, e percebendo no tópico da revolução como assunto para jovens a desculpa que possibilita aos mais velhos bater em retirada (ou ainda, simplesmente, para compartilhar a sensação de impotência tantas vezes verbalizada no filme), o rapaz ataca o ideal de uma juventude gloriosa, ativa, agressiva, em que estaria depositado um papel a cumprir.

Tem-se aí uma questão relevante: as construções em torno de um ideário da juventude frequentemente dizem respeito menos a uma afirmação de si do que a um discurso sobre o outro ou, pelo menos, a uma reminiscência. Afinal, não dá no mesmo que a juventude como subjetividade política seja reconhecida como lugar próprio ou, pelo contrário, esboçada a partir de uma posição de presumida exterioridade ${ }^{3}$. De qualquer forma, ambas as situações envolvem um forte grau de idealização, e ainda que a pergunta acerca de quem tece essas imagens juvenis não careça de relevância, sua colocação em primeiro plano nos conduziria a um caminho sem saída: a especulação sobre os intuitos de uma instância autoral que pode ou não estar imbuída do caráter nostálgico que acreditamos vislumbrar. Mais interessante seria, então, perguntar pelas potencialidades que tais imagens revelam quando articuladas como fragmentos, acenando para um tipo de experiência tida como irremediavelmente

\footnotetext{
${ }^{3}$ No cinema de Téchiné, a consciência acerca da qualidade em certa medida retrospectiva desse olhar sobre a juventude é constantemente assimilada diegeticamente, na figura de personagens mais velhos e geralmente intelectualizados. A diferença geracional é colocada em cena em vários de seus filmes. Em J'embrasse pas (1991), através da tutela que Romain (Philippe Noiret) oferece a Pierre (Manuel Blanc) e que é por este constantemente rejeitada. Também em Les témoins (2007), quando o médico Adrien (Michel Blanc) afirma, após um comentário malicioso do jovem Manu (Johan Libéreau), que entre os homossexuais quase todas as barreiras estariam superadas - raça, classe, religião - exceto a idade, que constituiria um verdadeiro fator de segregação. Mas é em Les innocents (1987) que um dos tropos comumente mobilizados para fazer referência ao frescor e à impetuosidade como marcas juvenis aparece de maneira mais explícita: para Klotz (Jean-Claude Brialy), regente de orquestra em crise pessoal e familiar, a juventude é a página em branco e é também o risco de preenchê-la.
} 
perdida e cuja realização terminamos por situar em um passado imaginado, relido por inúmeras camadas de discursos e formas culturais. Se a nostalgia, conforme argumenta Linda Hutcheon (1998), está, assim como a ironia, mais nos olhos de quem vê ${ }^{4}$, discuti-la em uma obra em especial nos permite mais do que apenas atestar 0 saudosismo de um diretor que pretenderia, com a releitura sentimental de um acontecimento - vivido ou não -, consumar algum tipo de restituição simbólica. Pelo contrário, ao sublinharmos o caráter nostálgico de uma imagem, voltamo-nos para a confrontação de algo que, idealizado, não pertence ao nosso tempo nem ao nosso espaço, mas que, por algum motivo, acreditamos ter sido possível antes. Na dialética entre desejar uma condição perdida e estar ciente da impossibilidade de sua realização ou restabelecimento no tempo presente, delineia-se a oportunidade de elaborar as formas desse desejo, de acessá-lo por meio das imagens e, a partir daí, compreender melhor aquilo que o orienta (COOK, 2005, p. 04). Na potência conferida pela "dimensão imaginativa e performativa" da nostalgia, abre-se então um espaço para vislumbrarmos aquilo que seria possível realizar a partir do que buscamos.

Ainda sobre a juventude como matéria de interesse estético e para além da questão de quem fala, cabe acrescentar que, no que se refere a certas conexões específicas com o campo da política, não se pode dizer que a formulação se mantenha sempre a mesma, nem que se estabeleça sempre com a mesma intensidade. Há gerações ou períodos históricos em relação aos quais opera mais fortemente a aproximação entre a figura do jovem como sujeito impetuoso, entregue à experimentação do sensível e capaz de expressar com convicção suas posturas mesmo quando assolado pela precariedade de suas certezas - e a juventude como subjetividade política determinante para o rumo das muitas disputas travadas ao longo do século passado. Os anos 1960, por exemplo, são um momento de intensificação desse tópico. Eles permitem como poucos discutir as inúmeras mediações que conduzem certos acontecimentos a um intrincado trabalho de elaboração. A essa altura, nem sempre parece importar tanto relativizar a participação concreta que um ou outro indivíduo de pouca idade tenha efetivamente desempenhado em quaisquer dos contextos específicos em que se desdobraram os embates de sua época; da mesma maneira em que pode ser cômodo esquecer que possivelmente houve jovens que, em plena contracultura, não se rebelaram muito ou sequer gostavam de rock. 0 modelo permanece, posto que se alimenta da genericidade. As nuances são depuradas ou temporariamente varridas para dar lugar a uma associação que alcança o status de mito, de modo que a dimensão objetiva de um fato histórico perde relevância face ao seu caráter icônico e aos modos mais sentimentais, ficcionais, pelos quais ele se inscreve no imaginário.

\footnotetext{
${ }^{4}$ Hutcheon (1998) argumenta que "nostalgia não é algo que você 'percebe' em um objeto; é o que você 'sente' quando dois diferentes momentos temporais, passado e presente, se unem para você e, com frequência, carregam considerável peso emocional. Nos dois casos [ironia e nostalgia], é o elemento de resposta - de ativa participação, tanto intelectual quanto afetiva que gera o seu poder". O que implica dizer, então, que ironia e nostalgia não são "qualidades de um objeto, mas respostas de sujeitos".
} 


\section{III}

Em paralelo às extensas correspondências entre a contracultura norteamericana e a suposta rebeldia inata dos adolescentes, ou entre o maio de 68 e certo modo de pensar a juventude, é no início dessa década que está, conforme dito anteriormente, o momento de crise e conflito que o filme de Téchiné irá explorar: a questão da Argélia, os impasses e divergências de interesses implicados na guerra que conduziu à sua independência.

Inicialmente encomendado para integrar uma série de trabalhos dirigidos por vários diretores para um canal de televisão francês, o episódio Le chêne et le roseau foi posteriormente transformado em longa-metragem com a realização de cenas adicionais. O próprio nome da série televisiva é sugestivo do tom que o filme iria assumir: "Tous les garçons et les filles de leur âge..." ${ }^{\prime 5}$, demarcando a noção de que há, sim, uma idade comum que amalgama as singularidades em torno de um sentido compartilhado, traços maiores que definem uma época. O seu espírito seria fortemente romântico, se lembrarmos a canção de Françoise Hardy a que o projeto faz alusão. Trata-se de um tempo no qual seriam vividas certas experiências únicas da juventude, e cuja sensibilidade estaria marcada pelas melodias pop e pelo descompasso, pela simultaneidade entre um idílio juvenil (que, ao menos na letra da música, é sobretudo dos outros) e o constante adiamento de sua realização. O tempo da juventude é de frescor, mas também é de monotonia e de espera.

O título do episódio, por sua vez, remete diretamente à fábula de Jean de La Fontaine sobre o carvalho e o junco. Em sua passagem para o cinema, a obra preserva no nome a menção aos juncos [roseaux] que, aparentemente frágeis, detêm, no entanto, uma maleabilidade vital que Ihes permite resistir às investidas do vento provação à qual o carvalho, aparentemente mais forte, não consegue resistir, dada a sua estrutura rígida ${ }^{6}$. Tomada como metáfora, a fábula recoloca a capacidade de adaptação e flexibilidade depositada nos jovens, mas a ultrapassa ao remeter ainda ao abalo sofrido por convicções que parecem insustentáveis quando confrontadas com o paroxismo de suas consequências. Tomar partido, aqui, implica assumir uma postura que repercute em todos os âmbitos da vida e que não se desvincula de um certo senso de responsabilidade cujos efeitos são, quase sempre, apresentados de modo bastante concreto. É a guerra - o horror da guerra, das vidas perdidas - o evento que instaura uma cisão e, com ela, uma passagem. É ela que provê os afetos que opõem Bartolo e Mariani, comunistas e pied noirs ${ }^{7}$; a chave que converte um pied noir em "assassino" e "porco da OAS"; o catalisador de um processo de transformação histórica que convoca a todos, demandando uma posição incisiva e não Ihes permitindo transigir, sob a pena de verem fraquejar suas certezas. É ela, enfim, que em certa medida orienta as relações: impõe quebras, supressões e também precipita os fatos. Sua força impele os

\footnotetext{
5 "Todos os garotos e garotas da sua idade..."

6 Trata-se, portanto, de uma imprecisão que o filme tenha sido lançado no mercado brasileiro com o nome Rosas selvagens. O título em português elide uma conotação que lhe é fundamental e que permanece explicitada pelo filme, na cena em que François lê o texto da fábula durante a aula.

${ }^{7}$ Assim eram chamados os colonos franceses que viviam na Argélia.
} 
jovens a uma maturidade precoce e eventualmente artificial, como a de Serge, chamado a cuidar de sua família, ocupando o lugar do irmão, marido e filho ausente, vitimado em combate.

Diante da suspeita dualidade entre acuidade e ilusão, certeza e perplexidade - e mesmo pelo seu poder de atacar binarismos - a guerra aparece como força devastadora que demanda a circunscrição de um locus capaz de fornecer ao sujeito chaves para situar-se em um contexto de turbulência, bem como para demarcar simetrias e distâncias em relação aos demais. Essa tomada de posição atuaria assim como recurso para organizar, mesmo que precariamente, a percepção de uma realidade traumática. Não obstante, dada a sua insuficiência para lidar com todas as nuances que coincidem em um contexto de intensificação e crise, tal demarcação requer ainda consciência em relação à parcialidade de seus postulados. A incapacidade de reconhecer esse caráter precário de qualquer certeza é parte daquilo que leva Madame Alvaréz, a mãe de Maïté, a sucumbir: o conflito entre a severidade de suas convicções e o sentimento de culpa pela omissão a que se havia prestado - ao recusar apoio a Pierre Bartolo, o irmão de Serge, em sua tentativa de deserção - exigem a confrontação de um problema para o qual as "verdades" fixadas não oferecem resposta ou conforto. A rigidez de suas convicções repercute em uma espécie de retirada de si, um alheamento elaborado durante a sequência da clínica. No caso de Alvaréz, todavia, não há remissões: seu retorno após o tratamento vem acompanhado da reafirmação dos antigos pressupostos. Sua condenação a Henri e o proclamado desinteresse que manifesta pelas questões que envolvem o futuro do estudante apontam para a mobilização de parâmetros de certo e errado que o Professor Morelli (Jacques Nolot), por sua vez, hesita em assumir, mostrando-se mais sensível aos problemas do seu aluno. A empatia para com o filho marcado pela imagem do pai morto e a determinação de ajudá-lo em seu trabalho de luto levam o professor a suspender o julgamento e a não aderir, de imediato, à indiferença da instituição em relação às escolhas daquele que, ainda muito jovem, assumiu o discurso do colono vitimador.

Tem-se aqui a questão da medida em que seria possível sensibilizar-se com motivações e dramas privados sem ver ruir os esquemas que estabelecem com rigor as divergências em torno de uma questão de cunho público. E, de fato, as divergências encontram espaço privilegiado de afirmação na sala de aula. A escola, como instituição onde o poder é sistematicamente encenado, permite as mais explícitas alusões a disputas ideológicas que são abertamente enunciadas e cuja legitimidade se afirma pela contaminação do político nas apreciações da matéria intelectual e estética. A cena em que se discute Rimbaud é significativa, nesse sentido. É também na escola onde são confrontadas de maneira mais dramática as perspectivas dos jovens e dos "nãojovens" - tensionados pelo conflito de autoridade e pelo distanciamento geracional, bem como pelas diferenças de classe, constantemente reiteradas inclusive no desnível que marca as expectativas dos adolescentes em torno da aquisição de uma cultura.

E se Morelli encarna de modo mais contundente a figura da perplexidade, ao sustentar a dúvida como único princípio confiável, François aparece como uma espécie de humanista romântico, sempre às voltas com suas descobertas amorosas e 
esforçando-se para estabelecer pontos de contato entre os outros jovens, transitando entre as posições discordantes e mediando encontros. Ao mesmo tempo, vê-se às voltas com o desafio de erigir para si uma imagem que assimile o novo dado de sua sexualidade. Como rapaz "experimentado", ele começa a fumar, passa uma noite ao relento na cidade com seu amigo e encontra sua própria maneira de expressar o anseio por uma vida sem tempos mortos: lamentando a parcela de sua existência desperdiçada com o sono. Seu maior desafio é encontrar um modo de vida que faça frente às ameaças assinaladas pelo seu desejo: os fantasmas da promiscuidade e da desagregação. Encarando-se frente ao espelho do banheiro, François designa para si um novo nome. Je suis un pedé ${ }^{8}$. Dizer a palavra depreciativa pode significar tanto um gesto de reprovação quanto o ritual em que se auto-denomina, com a repetição da frase demarcando talvez o momento em que a agressão é convertida em afirmação de si. É importante ressaltar, no entanto, que esse gesto não pressupõe necessariamente qualquer tipo de filiação identitária, mas demarcação de uma singularidade. Como certa vez afirmou Téchiné, "há tantas formas de sexualidade quanto há indivíduos" (citado em MARSHALL, 2007, p. 85).

Uma cena em particular sugere essa inadequação intrínseca a qualquer categoria e, em ultima instância, a impossibilidade de constituir marcos capazes de nomear o desejo. Na busca por uma referência, por alguém que conceda uma ancoragem moral à sua deriva desejante, François vai ao encontro do Senhor Cassagne. Homossexual, dono de uma sapataria, com um relacionamento estável, Cassagne seria aquele supostamente capaz de indicar um caminho para restituir-lhe à ordem de sua idealização romântica. O encontro - marcado por forte estranhamento é prematuramente interrompido, de modo que a conversa não chega a acontecer.

\section{IV}

Ainda sobre a guerra, é importante assinalar que ela está sempre ausente do campo do visível, sendo apenas um signo fantasmagórico evocado em cada uma das situações, e a justificativa - sem dúvida pertinente e até mesmo óbvia - de que ela esteja ocorrendo na Argélia enquanto a ação se passa na França não explica, sozinha, a opção por elidir qualquer referência imagética direta ao campo de batalha ou à situação na colônia. Tal ausência contribui para acentuar esse caráter de acontecimento maior que orienta, com suas capilarizações e seus mais minuciosos desdobramentos, a intimidade.

As operações levadas a cabo em Les roseaux sauvages não se distanciam, neste sentido, de outros filmes do mesmo diretor. É o caso de Les égarés (2003), no qual a investida dos alemães sobre o território francês durante a segunda guerra constitui o motivo inicial que é deslocado quando um desvio vem colocar em primeiro plano as dinâmicas relacionais que se estabelecem entre a família em fuga de Odile (Emmanuelle Béart) e o jovem misterioso que a eles se une. Assim, as imagens iniciais de um comboio e do bombardeio que o desarticula são a sugestão momentânea do

\footnotetext{
8 "Eu sou uma bicha".
} 
panorama de um acontecimento histórico que perde progressivamente sua centralidade, até o ponto em que se torna difícil atestar sua permanência: isolados em uma casa abandonada, os personagens desconhecem os desdobramentos da guerra e perdem de vista o seu desfecho ${ }^{9}$. O conflito que interessa é sobretudo aquele que ocorre quando indivíduos são conduzidos pelas circunstâncias a um convívio que se estabelece sem as mediações que supostamente permitiriam uma aproximação segura. Dito isto, caberia, no entanto, ressaltar uma diferença evidente entre os dois filmes, que é o fato de que neste, em particular, o diretor faz uso expressivo de imagens de arquivo.

Em Les roseaux sauvages, por outro lado, insisto que a guerra - sua marca epocal mais eloquente - não chega a ser colocada em cena. Quando muito, tem a sua presença demarcada a partir de elementos alusivos: nos uniformes militares dos convidados do casamento ou nos ruídos do rádio em que Henri se coloca à escuta, em permanente vigília. Isso não se restringe, porém, apenas à guerra. Não há propriamente o que poderíamos chamar de reconstituição de época, se assim entendemos o esforço para lograr uma representação verossímil que recubra, mediante um trabalho exaustivo, toda a amplitude da diegese. Tal exercício buscaria não apenas aludir a um momento histórico, mas saturar o campo do visível de composições detalhadas e informações contextuais que abrangessem desde as minúcias quase imperceptíveis até a magnitude dos eventos extraordinários comumente relacionados ao período. No caso específico de uma guerra, a vastidão dos campos de batalha, as explosões e as mortes, o inventário de armas, uniformes e equipamentos, os amplos contingentes de soldados, as dependências hospitalares e mesmo os espaços em que ocorrem as manobras políticas dos dirigentes viriam todos integrar o excedente capaz de imprimir a uma obra o seu status "de época". Les roseaux sauvages se distancia de tal estratégia, restringindo-se a um pequeno número de referências que seriam emblemáticas, não necessariamente do período, mas de todo um imaginário constituído pelos repertórios da cultura. Em uma economia cênica que privilegia os atores e os diálogos, seus encontros e dinâmicas, a época se encontra antes condensada em roupas, carros, filmes em cartaz no cinema de bairro, Beach Boys, danças, Let's twist again - e com mais força, ao final, Runaway, de Del Shannon.

Seria mesmo possível argumentar que tal opção estética se encontra estritamente relacionada ao fato de que a conexão entre o caráter contingente das perspectivas pessoais implicadas e o panorama mais geral da grande história nunca é de todo evidente; antes, a relação permanece constantemente problematizada. O que implica dizer, afinal, que o filme não postula tal correspondência desde uma instância enunciativa que precede os adolescentes, mas os acompanha em sua hesitação e, nesse sentido, torna-se cúmplice dos atos de fala com que eles repõem o vínculo entre sua educação sentimental e os desdobramentos da política.

\footnotetext{
${ }^{9}$ Tal confinamento, de fato, caracteriza a posição de Odile e dos seus filhos. O mesmo não ocorre com Yvan (Gaspard Ulliel), que, afastando-se com frequência da casa para caçar e saquear os corpos dos soldados e civis mortos, mantém um vínculo direto com a guerra e acompanha os seus rumos. A tensão se dá também, então, pelo desnível que marca essas diferentes percepções acerca do contexto mais amplo no qual os personagens estão inseridos.
} 
A assunção desse viés decerto implica a rejeição ao atrativo de perceber no grupo de jovens a configuração de um microcosmo. Esse tipo de apreciação é frequentemente mobilizado para a análise de outras obras, como ocorre, por exemplo, com The dreamers (2003), de Bernardo Bertolucci - com a diferença de que, nesse caso, tal abordagem não se mostra de todo injustificada, já que o filme parece estar organizado justamente para sugerir um paralelismo entre a agitação que toma conta das ruas durante o maio francês e os jogos eróticos que ocorrem no apartamento onde os protagonistas permanecem confinados. A conciliação última entre as duas instâncias que corriam em presumida correspondência - as barricadas e o espaço da intimidade - ocorreria quando uma pedra rompe a vidraça, reintegrando os jovens ao âmbito da contenda pública que até então figurava como pano de fundo. Meu argumento é o de que o filme de Téchiné, por outro lado, afasta esse tipo de leitura ${ }^{10}$.

Ao lado da guerra como grande acontecimento ritualizado nas vidas cotidianas pelo desdobramento de seus sistemas de oposição, encontram-se outros rituais, eventos sem dúvida menores, mas que, na intimidade, interpõem-se como definitivos. Tais eventos não são independentes, mas, pelo contrário, intrinsecamente relacionados ao fato maior da guerra. O tempo do filme é demarcado por duas cerimônias: um casamento e um funeral. O primeiro, uma tentativa de não voltar ao combate; o segundo, um resultado deste. Na eloquência de ambos, a parcela de fatalidade que decorre das circunstâncias alheias à vontade imediata; a medida em que as vidas podem ser orientadas desde uma instância exterior, fora de controle. A disposição para abraçar alguma resolução categórica é considerada pelos mais jovens a partir de suas próprias perspectivas - como quando Serge decide casar-se com sua cunhada, ou quando Maïté encontra na doença da mãe um problema que se sobreponha às suas inquietações mais íntimas -, mas não raramente cala com a recolocação persistente de questões supostamente triviais em face dos grandes acontecimentos. Serge, afinal, não se casa; François se despede de Henri sem chegar a elucidar os termos do encantamento que o impele a uma tentativa de aproximação; e Maïté confronta uma vez mais sua dificuldade em lidar com garotos.

Não por acaso, François e Maïté remetem a dois sujeitos políticos que ganhariam relevância e expressividade ao longo da década: os homossexuais e as mulheres. Estas duas categorias indicavam, então, uma rearticulação da política, na medida em que colocavam sob suspeita a capacidade que os discursos abrangentes teriam de incorporar diferenças e conciliar demandas. Como dito anteriormente, o filme de Téchiné ao mesmo tempo traz à tona essa questão e a tensiona, não apenas porque explora os limites dessa política de identidades, mas também porque, nele, é ainda a dimensão nacional e os grandes sistemas de pensamento que, para dizer de algum modo, sobredeterminam os posicionamentos dos personagens, atribuindo força e complexidade aos seus conflitos. A certa altura François adverte que Maïté é

10 Para outra abordagem comparativa entres os filmes de Bertolucci e Téchiné, proposta em outros termos e a partir de outros interesses, cf. Monassa. 
"comunista, feminista, idealista e materialista", demarcando com isso a indissociabilidade que se estabelece entre as convicções que sustenta e o caráter arredio e contundente de seu comportamento.

O auge dessa mediação ideológica ocorre durante a passagem de Henri pelo partido comunista, onde encontra Maïté. Ali os dois finalmente se conhecem, tão antagônicos quanto podem ser, dadas as suas posições. A leitura de uma carta coloca em pauta o extravio dos franceses argelinos repatriados, assinalando uma abertura, um ponto de aproximação. A desarticulação das famílias de ambos e a experiência de um tempo marcado pela indefinição remetem a situações que, embora divergentes, mostram-se igualmente condicionadas pelos desdobramentos de um mesmo processo. Tal instância de reconhecimento é, no entanto, prematuramente aniquilada quando Henri revela sua disposição inicial: incendiar a sede do partido. Neste ponto, a divergência política vem restituir o jogo de antagonismos anteriormente estabelecido.

Armond White (1995, p. 70) já havia chamado a atenção para essa articulação conflituosa entre amor e política no filme, na medida em que o triângulo amoroso típico seria aí apresentado, também, "como um diagrama de posições morais e políticas". Segundo White, é na estrutura do melodrama que o diretor encontra a forma de apresentar essa tensão:

Seu interesse analítico em uma forma comumente devotada à primazia da emoção sobre o intelecto responde a uma necessidade particular da ideologia sexual: reconciliar sexo e papéis sociais; entender identidade como um produto de condicionamentos culturais. (WHITE, 1995, p. 70, tradução minha). ${ }^{11}$

No caso de Maïté e Henri, se desejo que não se curva aos esquemas de classificação e de oposição. A essa altura somos confrontados o desentendimento que se interpõe entre ambos não vem selar a separação definitiva - a eles será reservado mais um encontro - é também porque há algo da ordem do com um desacerto entre atração, curiosidade e repulsa, diante do qual as conviç̧ões políticas nem se mostram plenamente suficientes, nem podem ser de todo descartadas: persistem como guia ou subterfúgio. $O$ impasse pode então se delinear como frequentemente 0 imaginamos: carregado de afecção e opacidade, colocando-nos à prova e desfazendo as hierarquias com que pretendemos organizar, por vezes de modo demasiadamente eloquente, o que conta e o que não conta.

Observar tudo isso é também uma maneira de demarcar que o conflito e a indeterminação perpassam todo o filme de Téchiné: nele não há nada semelhante a lamento ou escapismo. A nostalgia em relação ao modo como a política pôde eventualmente incidir como elemento decisivo na conformação de um rito de passagem ou experiência de transformação na juventude indica o reconhecimento mesmo de que essa possibilidade de mediação seja postulada como uma questão que vale a pena ser enunciada. Lançar mão do passado faria parte, então, do exercício de pensar o político e o histórico não como matérias alheias, mas imbricadas na própria

${ }^{11}$ No original: "His analytical interest in a form usually devoted to the primacy of emotion over intellect answers a particular need in sexual ideology: to reconcile sex and social roles, to understand identity as a product of cultural conditioning". 
experiência da intimidade. E se a imaginação nostálgica permite "articular criativamente um sentimento de inadequação frente ao aqui e agora mediante certos artefatos culturais" (PRYSTHON, 2009, p. 9), acredito que essa inadequação, aqui, advém não tanto da constatação de uma falência dos modos pelos quais podem ser pensadas tais conexões, mas pela desconfiança de que a fratura entre sujeito e história se torna mais aguda devido aos efeitos de uma imediaticidade que borra os contornos do presente.

O esforço para proceder à recuperação imaginativa de uma experiência de passagem, condensada no recorte de uma trajetória ainda em formação, é também o anseio pela abertura propiciada por um tempo adolescente que, ainda não saturado de obrigações, convida à possibilidade de provisoriamente co-existir. Muito poderia ser dito sobre essa particularidade que os filmes de Téchiné apresentam, qual seja, a de constituir comunidades provisórias. Aquilo que agrupa seus personagens é em certa medida uma qualidade que os unifica: sejam eles desgarrados, inocentes, ladrões ou testemunhas ${ }^{12}$, há algo que torna possível sua convergência em torno de uma denominação que é também o elemento instaurador de uma cumplicidade. O choque de uma experiência traumática que toma de assalto os sujeitos e os converte em protagonistas sem defesas, depositários da angústia resultante da irrupção de um fato que se apresenta de modo ainda disforme - como o foi a questão da AIDS no início dos anos 1980, em Les témoins (2007) - é também a substância de um relato possível. E a generosidade que marca tais obras, se é possível falar deste modo, está não apenas na obstinação com que elas se prestam a acompanhar os personagens no esforço com que elaboram suas histórias - algo poderia ser dito sobre a verborragia dos personagens de Téchiné -, mas também no fato de que a eles é concedida a oportunidade de não permanecerem sozinhos.

Em Les roseaux sauvages, o momento de suspensão temporal que favorece o encontro decisivo ocorre durante a espera pelo resultado dos exames finais. O lugar para os últimos desdobramentos é o de um rio onde toda a sequência final se desenrola. Maïté - e é com ela que termino - reencontra Henri, e nessa ocasião as divergências são colocadas em um parêntese, bem como a cisão entre o desejo sexual - a respeito do qual ela havia se mostrado sempre evasiva - e o amor romântico que ela renega. Tal desfecho, no entanto, coloca um impasse: um plano nos mostra Henri indo embora e, logo em seguida, vemos Maïté sozinha em quadro. Nesse momento, ela empreende uma corrida em direção a François até que o alcança e, chorando, cobre a sua face de beijos.

Se esta corrida não se abre a uma leitura fácil é porque não nos permite definir com precisão se o que está aí implicado é um valor de negação - no caso, negação da incerteza que se instaura quando abandonamos os esquemas que regulam a proximidade ou o distanciamento em relação aos demais - ou de afirmação - de um vínculo precioso cuja importância se reafirma frente à impermanência de todo o resto. Dito de outro modo: talvez não seja possível decidir se o impulso que impele Maïté ao encontro de François indica um rechaço ao desarranjo que viria minar a posição

\footnotetext{
12 Refiro-me aos filmes Les innocents (1987), Les voleurs (1996), Les égarés (2003), Les témoins
} (2007). 
segura, reativa, que até então Ihe circunscrevia simultaneamente uma conduta sexual e uma obstinação política; ou se alude à valorização de um laço de cumplicidade que não necessariamente substitui nem ultrapassa as particularidades de uma relação amorosa, posto que se inscreve para além de toda definição, como um afeto sem nome ${ }^{13}$.

\section{VI}

O sentimento nostálgico se apresenta como uma estrutura complexa que se desdobra em múltiplas temporalidades e instâncias de apreciação. Temos a nostalgia sugerida por um registro que, em meados dos anos 1990, no contexto da última virada de século, revisita o imaginário político e cultural dos anos 1960 e os seus emblemas, elaborando ao seu modo essa época mítica. Também a nostalgia de um passado não-vivido, presente em alguém que - como eu, adolescente - viu o filme pela primeira vez em meados dos anos 1990 e encontrou aí outro modo, dentre muitos, de fantasiar um período anterior desconhecido e de pensar a forma da política que, com ele, seria oferecida às gerações posteriores. Nostalgia, ainda, do tempo presente sobre os agora saudosos anos 1990, quando ao rever o filme relembro o anseio por uma conexão orgânica entre juventude e política, articulação que hoje me parece menos urgente, levando a nostalgia que senti primeiro a desvanecer-se, sendo substituída por esta outra, mais recente: a nostalgia pelo meu passado, que agora releio a partir das imagens que o povoaram.

As muitas maneiras de encadear e de relacionar décadas (1960-1990-2010), bem como a coexistência ou justaposição destes anos, permitem-nos apenas vislumbrar uma multiplicidade de leituras potenciais. Quantas outras nostalgias possíveis não poderíamos intuir a partir dos incontáveis modos em que a passagem dos anos se articula para expressar algo que certa vez podemos ter desejado para as nossas vidas? - uma relação segura como ancoragem para o extravio de alguém no mundo, uma ética social que oriente as relações, um esquema que nos permita classificar a realidade, uma ideologia que inscreva nossas vivências em um marco coletivo, compartilhado. O cinema, nesse sentido, poderia ser visto como chave que ativa a capacidade de colocarmos a nossa própria experiência em perspectiva, aguçando com isso um senso de historicidade, nos termos propostos por Fredric Jameson:

uma percepção do presente como história, isto é, como uma relação com o presente que o desfamiliariza e nos permite aquela distância da imediaticidade que pode ser caracterizada finalmente como uma perspectiva histórica. (JAMESON, 2007, p. 290).

\footnotetext{
${ }^{13}$ Gilles Deleuze e Félix Guattari (1992, p. 226-7) falam do "grande romancista" como um artista que "inventa afectos não conhecidos ou desconhecidos, e os faz vir à luz do dia". Podemos, com isso, pensar a matéria estética como aquela que permite criar novos afetos. Assim, segundo os autores, "quando Emily Bronté traça o liame que une Heathcliff e Catherine, ela inventa um afeto violento (que, sobretudo, não deve ser confundido com o amor), algo como uma fraternidade entre dois lobos."
} 
Para Jameson, seria essa capacidade de enxergar o presente com distanciamento aquilo que permite aos indivíduos não apenas situar sua experiência do aqui e agora dentro de uma cadeia temporal mais ampla, orientada, como também o que permite falar propriamente em "anos 50", "anos $80^{\circ}$ ou, como é o caso aqui, "anos 60" - ou seja, condensar o tempo em rótulos, datas, décadas, períodos, gerações. O exercício de pensar a experiência do tempo presente como passado e como história implica, assim, imaginar os termos nos quais ele poderia ser narrado. A minha discordância se dá em relação à ideia de que uma estética que assuma o passado como citação e como colagem de referências aponte necessariamente para qualquer indício de que seríamos menos capazes, hoje, de experienciar a história. Talvez, pelo contrário, o que o adensamento dessas ideias em emblemas nos proporcione seja uma maior autoconsciência em relação ao status em certa medida inventado desse passado que se conta, bem como a consolidação da suspeita que recai sobre a possibilidade de qualquer reconstituição.

Vendo como se contam essas histórias, como se encadeiam as múltiplas instâncias temporais, desde uma menor até uma maior amplitude - o tempo pessoal, o tempo familiar, o tempo da nação -, aprendemos a elaborar nossas próprias trajetórias, situando-nos no marco da "época" que nos coube viver, esperando encontrar aí algo como uma correspondência que seria preciso intuir. O sucesso das formas culturais que evocam os grandes fatos da história como panos de fundo para o desenrolar das vicissitudes de uma vida qualquer talvez esteja relacionado também à persistência de algumas indagações e curiosidades: o que dirão da nossa época, no futuro? Estaremos contemplados nos estereótipos que dela se formem ou, pelo contrário, pareceremos anacrônicos? ${ }^{14}$ Teremos tomado parte nos momentos tidos como determinantes, aqueles que ficarão marcados na memória das gerações futuras? Soubemos reconhecê-los em sua devida importância? Por trás dessas perguntas, e em especial da última, uma outra que talvez ajude a entender a ansiedade que permeia estas questões e que nos impele à tentativa de antecipar suas respostas: saberemos reconhecer os eventos que nos ultrapassam e dos quais raramente temos uma visão abrangente mas que, não obstante, condicionam nossa existência?

Intuir a própria vida como uma biografia, subsumindo ou destacando detalhes, impondo certa ordem à dispersão, costurando causas e efeitos onde tal relação pareceria incerta, atuando enfim como ficcionistas que contam o passado para assim fixar-lhe um sentido: é para isso que servem também as imagens midiáticas, as ideologias políticas, as narrativas de formação, os ritos de passagem. Daí a eficácia dessas operações e a potencialidade nostálgica de um filme que, como o de Téchiné, mobiliza tais recursos. Além disso, o que este filme, em especial, em determinado ponto elabora é uma estética da relação possível entre as vidas dos jovens e a política, pensada de modo que nem mesmo as "causas" do amor apareçam como

\footnotetext{
${ }^{14}$ Esses traços determinantes têm sido apresentados pela mídia, em grande medida, em termos de referências e alusões a comportamentos, modas, gostos musicais. Para demarcar a possível relevância de tais perguntas talvez seja necessário, então, lembrar que o compartilhamento desses valores e estilos aponta para um senso de pertencimento. O jogo de legitimação de referências e de atribuição de prestígio a certos segmentos, dentro do universo da cultura pop, não deixa de constituir, também, uma disputa pela fixação dos estereótipos que correspondem a cada período.
} 
independentes da causa política e de suas contingências, posto que entre o pessoal e o nacional-coletivo existem linhas de continuidade que os tornam difíceis de serem desvencilhados. Se essa relação não se dá sem conflitos, tampouco parece haver uma descrença absoluta em relação às múltiplas maneiras pelas quais estas distintas instâncias podem ser pensadas em conexão. Nesse sentido, Les roseaux sauvages se dedica a um trabalho de sobreposição entre normas sociais, posições políticas, expectativas românticas e paixão erótica, percorrendo seus múltiplos entrelaçamentos para então demarcar a irredutibilidade do desejo.

Por fim, no que diz respeito às fantasias de uma juvenil impetuosidade, sempre à flor da pele, cabe destacar que o seu aspecto mais problemático talvez resida no fato de que, para além de sua provável generalização ou arbitrariedade, ao atrelar o compromisso político ou amoroso ao frescor da idade imatura, tais representações estariam de certo modo relegando a política a um espaço de ingenuidade; estabelecendo a condição de não saber como a única possível para acreditar e, portanto, para o envolvimento.

\section{Referências}

COOK, Pam. Screening the past: memory and nostalgia in cinema. London and New York: Routledge, 2005.

DELEUZE, Gilles; GUATTARI, Félix. O que é a filosofia? Tradução de Bento Prado Jr. e Alberto Alonso Muñoz. Rio de Janeiro: Ed. 34, Coleção Trans, 1992.

HUTCHEON, Linda. Irony, nostalgia and the postmodern. University of Toronto English Library, 1998. http://library.utoronto.ca/utel/criticism/hutchinp. html. Acesso em 07 jan. 2012.

JAMESON, Fredric. Pós-modernismo: a lógica cultural do capitalismo tardio. 2. ed Trad. de Maria Elisa Cevasco. São Paulo: Editora Ática, 2007,.

MARSHALL, Bill. André Téchiné (French Film Directors). Manchester and New York: Manchester University Press, 2007.

MONASSA, Tatiana. Rosas selvagens. Contracampo. Disponível em: http://www.contracampo.com.br/67/rosasselvagens.htm. Acesso em 15 jan. 2012.

PIGNATARI, Decio. 0 retrato do amor quando jovem. São Paulo: Cia das letras, 1997.

PRYSTHON, Angela. A imaginação nostálgica como utopia. Revista Tatuí, no 5, (edição do Passado). Recife: 2009, pp. 7-10.

SARLO, Beatriz. Cenas da vida pós-moderna: intelectuais, arte e videocultura na Argentina. Trad. de Sérgio Alcides. Rio de Janeiro: Editora da UFRJ, 2004, $3^{a}$ ed.

WHITE, Armond. Strange gifts: André Téchiné remakes the melodrama. Film Comment, 31 (Julho-Agosto), 1995, pp. 70-75. 


\section{Title}

Love passions, political passions

\section{Abstract}

This essay aims to take part in the studies on the prolific relations between cinema and nostalgia. I seek to discuss how a film by French director André Téchiné, Les roseaux sauvages (1994), addresses youth as a moment of intensification, openness and incertitude, by situating the dramas and conflicts of its characters within the context of 1962 's France, during the final moments of the Algerian war. Despite of the film's subject and its potential autobiographic connotations, I argue that nostalgia here should be explored less in the authorial dimension than through its reassessment of cultural artifacts and also in its articulations between love, history and politics. Nostalgia is here understood as a complex structure of multiple superimposed temporalities in which the spectator is necessarily implied. In this sense, nostalgia involves an affective engagement and a subjective response that I make explicit.

\section{Keywords}

Cinema. Nostalgia. Youth. Love. Politics.

Recebido em 15/04/2012. Aprovado em 20/10/2012. 
